\title{
LIBERTAD Y NECESIDAD EN THOMAS BRADWARDINE
}

\author{
Ignacio Verdú Berganza \\ Profesor de Filosofía
}

\begin{abstract}
RESUMEN
Thomas Bradwardine fue, con Guillermo de Ockham, tal vez el pensador más destacado del siglo XIV. Influyó en los terrenos de la lógica, la ciencia (matemáticas y física) y la teología. Su obra más importante fue: De Causa Dei contra Pellagium et D e virtute causarum. En ella aborda profundamente un problema fundamental, discutido antes y después (sobre todo en los siglos XVI, XVII y XVIII): el de la libertad del hombre, el de la posible concordia entre necesidad y libertad.
\end{abstract}

Palabras clave: Bradwardine, libertad, necesidad.

\begin{abstract}
Thomas Bradwardine was - perhaps whith William of Ockham - the greatest thinker of the fourteenth century. His influence was felt in the fields of logic, science (mathematics and fhysics), and theology. His most important book is DE CAUSA DEI CONTRA PELLAGIUM ET DE VIRTUTE CAUSARUM. In this work, he addresses an issue that had already been thoroughly discussed amongst philosophers (and that will be revisited, especially in the $16^{\text {th }}, 17^{\text {th }}$ and $18^{\text {th }}$ centuries): the problem of human freedom and the need to reconcile necessity and liberty.
\end{abstract}

Key words: Bradwardine, liberty, necessity.

«Sin ninguna duda, los dos pensadores más influyentes y destacados de la primera mitad del siglo XIV fueron Guillermo de Ockham y Thomas Bradwardine; su influencia en generaciones futuras en Oxford y en otros lugares fue extraordinaria». ${ }^{1}$

Estas palabras de J. A. Weisheipl no resultan exageradas, lo que podemos comprobar acudiendo a los trabajos dedicados a estudiar la figura de Thomas Bradwardine, el Doctor Profundus. Y fueron tres los campos en los que este hombre, conocido también como Magnus Logicus o Egregius Theologus, destacó y ejerció una indudable influencia tanto en su siglo como en los posteriores: el de la lógica, el de la filosofia natural (tanto en lo referido a la física como a las matemáticas) y, desde luego, el de la teología. ${ }^{2}$

En el presente artículo, con la brevedad y concisión que exigen las circunstancias, voy a centrar mi atención en el terreno antropológico-teológico; muy especialmente en sus reflexio-

1 J. A. Weisheipl, «Ockham and the Mertonians», en The History of the University Of Oxford, vol. I: The early Oxford Schools, j. I. Catto/R. Evans (eds.), Clarendon Press, Oxford, 1984, C. 16, pp. 607-858.

2 Una visión general de cuál fue la aportación de Bradwardine en los campos de la matemática, la fisica, la lógica y la teología se encuentra en: I. Verdú Berganza, Tomás Bradwardine. El problema de la libertad, EUNSA, Pamplona, 2001, pp. 77-103; y sobre los estudios dedicados a su pensamiento pp.18-24. 
nes en torno a la relación entre Dios y el hombre, a la posibilidad o imposibilidad de concordia entre necesidad y libertad.

Durante la primera mitad del siglo XIV, especialmente en el segundo cuarto, se multiplicaron en Oxford, donde estudiaba y escribía Thomas Bradwardine ${ }^{3}$, las discusiones en torno a la presciencia divina, la predestinación, los futuros contingentes, el libre albedrío, la gracia, la salvación, la potencia divina,...En palabras de un contemporáneo de Bradwardine, Thomas Buckingham, se buscaba el medium catholicum entre el error de Pelagio y Cicerón por un lado, y el determinismo fatalista (claramente condenado por Esteban Tempier en 1270 y 1277) ${ }^{4}$ por otro.

Será en este contexto en el que las tesis defendidas por Bradwardine chocarán con las defendidas por pensadores como Pedro Aureolo, Ricardo Fitzralph, Guillermo de Ockham, Juan de Mirecourt, Gregorio de Rimini, Roberto Holcot, Adam Wodeham, Thomas Buckingham o Nicolás de Autrecourt.

El asunto es importante. No es una mera discusión de escuelas. Es una concepción del hombre y del mundo lo que está en cuestión; un modo de entender la existencia y la dignidad humanas.

Durante este periodo de tiempo, el problema de la relación de la voluntad divina con la humana se discute con un vigor, un rigor y una sutileza dificilmente superables; de hecho, como veremos, en los siglos XVI y XVII se repetirán los argumentos, tanto en el terreno protestante como en el católico. ${ }^{5}$

La omnisciencia y la omnipotencia divinas, su providencia, su modo de actuar sobre el mundo y en particular sobre el hombre, el papel de éste en el universo, la predestinación divina, la necesidad de Dios y sus decretos, la libertad del hombre y sus acciones, la contingencia, la gracia, el mérito..., éstas son las cuestiones que ocupan la atención, el interés, del Doctor Profundus; son los asuntos a los que dedica una muy importante parte de su producción intelectual: el De futuris contingentibus ${ }^{6} \mathrm{y}$, sobre todo, su obra más importante, extensa e influyente, el De causa Dei contra Pelagium et de virtute causarum ${ }^{7}$, en la que, de aquí en adelante, centraré mi atención de modo preferente.

El objetivo que buscaba Bradwardine al escribir esta monumental obra, como el mismo indica, no era otro que el de refutar las opiniones de los que él denomina «pelagianos modernos» referidas al hombre y al poder de su libertad, exponiendo sus propias opiniones y haciendo hincapié en nuestra dependencia respecto de Dios. ${ }^{8}$ Sus tesis, por tanto, deben entenderse en un contexto muy particular, el de, tal y como él lo entiende, una necesaria reacción contra un renovado pelagianismo. Y Así, conocer adecuadamente sus planteamientos exige, previamente, comprender por qué habla Bradwardine de «modernos pelagianos» y quienes serían estos.

Aproximadamente entre 1330 y 1340 , en Oxford, se produce un considerable aumento de los ataques dirigidos al pelagianismo. Esta reacción tiene como protagonista fundamental al

3 Para recabar datos sobre la vida de Thomas Bradwardine remito a la obra ya citada: I. Verdú Berganza, Tomás Bradwardine... pp. 11-15 y 25-30.

4 Thomas Buckingham, De contingentia futurorum, conclusio 10, New Coll. MS 134, f 343va; Ed. J. F. Genest, p. 260. Para conocer la figura de Thomas Buckingham y su relación con Bradwardine es recomendable leer: J. F. Genest, Prédétermination et liberté créée à Oxford au XIVe siècle (Buckingham contre Bradwardine), VRIN, París, 1992.

5 Información interesante a este respecto puede encontrarse en: I. Verdú Berganza, «Precedentes medievales de las disputas sobre la libertad en las escuelas de Salamanca en los siglos XVI y XVII», Cuadernos Salmantinos de filosofia, $\mathrm{n}^{\circ} \mathrm{XXX}$, Universidad Pontificia de Salamanca, 2003, pp.291-313.

6 J. F. Genest, «Le de futuris contingentibus de Thomas Bradwardine», Recherches Augustinienses, 1979 (14), 249-336.

7 Thomas Bradwardinus, De Causa Dei, contra Pelagium, et de virtute causarum, ad suos Mertonenses, libri tres, Ed., Henry Savile, Londini, 1618. En lo sucesivo citaré abreviadamente el nombre del autor (Th. Bradwardine) y remitiré, en la paginación, a la aludida edición.

8 Th. Bradwardine, De Causa Dei, Lib. I, Cap. 35, p. 308 C-D. 
neo-agustinismo pujante del momento que se enfrenta a aspectos concretos del pensamiento franciscano de la época con respecto a la gracia y la justificación. ${ }^{9}$ El De causa Dei no es, pues, el inicio de la crítica o la discusión; aparece en el fragor de la contienda y representa, en todo caso, el momento cumbre de la reacción frente al llamado semi-pelagianismo.

Un buen número de pensadores, tras las condenas parisinas de Esteban Tempier, habían centrado sus esfuerzos en defender la libertad tanto de Dios como del hombre, y algunos de ellos defendieron posiciones de tendencia «semi-pelagiana», como queda patente en las discusiones del momento acerca de los futuros contingentes. ${ }^{10}$

En el prefacio de su obra fundamental Thomas Bradwardine nos hace saber que consintió en escribirla en respuesta a varias y repetidas peticiones, y en la esperanza de que pudiera ayudar a que se volviese a la fe establecida ${ }^{11}$; para lo cual creaba el De causa Dei como parte de una especie de cruzada contra los nuevos pelagianos. ${ }^{12}$ Según el Doctor Profundus estos «modernos pelagianos» anteponen el libre querer humano al querer divino, siguen a Pelagio en lo que respecta a su doctrina sobre el libre albedrío, menospreciando la gracia, pues consideran al libre querer humano como algo capaz, por sí mismo, de alcanzar la salvación. ${ }^{13}$

A lo largo del De causa Dei, en multitud de pasajes, podemos leer ataques directos a los pelagianos y a sus posiciones, sin embargo, aunque Pelagio y Casiano son nombrados explícitamente en distintas ocasiones, queda omitido el nombre de los «modernos pelagianos» que han provocado la reacción de Bradwardine. La identificación de los mismos es pues fruto de la investigación y de la conjetura.

Estudiosos como H. A. Oberman, J. A. Weisheipl, J. F. Laun, G. Leff o J. A. Robson ${ }^{14}$ coinciden en señalar a Ockham y a aquellos pensadores que defendieron posiciones cercanas a las del Venerabilis Inceptor respecto de los futuros contingentes, la predestinación divina, la gracia y el mérito, como los destinatarios de la respuesta del Doctor Profundus. Junto a Guillermo de Ockham, pues, habría que nombrar a hombres como Durando de Saint Pourçain, Pedro Aureolo, Roberto Holcot, Adam Wodeham o Thomas Buckingham.

Ahora bien, comprender la propuesta del Doctor Profundus respecto de Dios y el hombre expuesta en el De causa Dei; en definitiva, entender su posición respecto de la necesidad de Dios y la libertad del hombre, exige tener presente no sólo su anti-pelagianismo sino también su rechazo frontal a todas aquellas teorías, fatalistas o necesitaristas, que menoscaben la libertad de Dios o del hombre.

Y así, en efecto, en su empeño por defender a Dios como primera causa, primer motor, omnisciente, omnipotente, providente y enteramente libre, salvaguardando la libertad propia del actuar humano, Bradwardine, en los tres libros que componen su obra fundamental, cita en multitud de ocasiones las famosas condenas de Esteban Tempier de 1270 y $1277 .^{15}$

9 W. J. Courtenay, «Augustinianismus at Oxford in the fourteenth Century», en Augustiniana, n³0, 1980 , pp. 58-70.

10 J. F. Genest, «Le de futuris contingentibus...», pp. 127-139.

11 Th. Bradwardine, De Causa Dei, Praefatio, p. 1.

12 Th. Bradwardine, De Causa Dei, Praefatio, pp. 7-8.

13 Th. Bradwardine, De Causa Dei, Praefatio, pp. 1-2.

14 J. A. Weisheipl, «Ockham and the...», p. 657; H. A. Oberman, «Thomas Bradwardine, un précurseur de Luther?, en Revue d'Histoire et de Philosophie Religieuses, n 40, 1960, pp. 146-151; J. F. Laun, «Recherches sur Thomas Bradwardine, precurseur de Wiclif», en Revue d'Histoire et de Philosophie Religieuses, $\mathrm{n}^{\circ} 11,1929, \mathrm{p} .218$; G. Leff, Bradwardine and the pelagians. A estudy of his «De Causa Dei» and its opponents, Cambridge University Press, Cambridge, 1975; J. A. Robson, Wyclif and the Oxford schools, Cambridge University Press, Cambridge, 1961.

15 I. Verdú Berganza, «El movimiento averroísta y el pensamiento de Thomas Bradwardine. Dos concepciones del hombre enfrentadas, en Actas del III Congreso Nacional de Filosofia Medieval, (Averroes y el averroismo), Zaragoza, 1999, pp.387-395; L. Bianchi, Il Vescovo e i Filosofi. La cndanna del 1277 e lévoluzione delláristotelismo scolastico, Bergamo, 1990; R. Hissette, Enquête sur les 219 articles condamnés à Paris le 7 Mars 1277, Lovaina, 1977. 
La situación presenta indudables semejanzas con la que se vivirá en los siglos XVIY XVII y que se conoce como la disputa «de auxiliis». ${ }^{16} \mathrm{De}$ hecho, el enfoque que hace Bradwardine del problema y las soluciones que plantea son un asombroso precedente de las que podemos encontrar en Báñez y sus seguidores cuando se enfrentan a Molina y los molinistas. Y así, reviviendo el ya mencionado neo-agustinismo de principios del XIV en Oxford y la reacción antipelagiana, podemos leer textos de Báñez como los siguientes:

«Después de este error (el de Pelagio), no dejó de haber algunas reliquias de aquel error, aún entre algunos fieles, pareciéndoles que se quitaba el libre albedrio por la doctrina de San Agustín, que enseñaba que el consentimiento del entendimiento y la voluntad a la fe de Jesucristo era efecto de la gracia y misericordia de Dios, y no porque el hombre pudiese por sus fuerzas naturales consentir a los llamamientos de Dios... Lo cual, quien lo viere todo, siendo teólogo desapasionado, conocerá que otras semejantes reliquias se levantan en nuestros tiempos con el titulo de defender el libre albedrio». ${ }^{17}$

«...Y es que en nuestros tiempos - qué pena- no faltan teólogos de la Compañía de Jesús, que ojalá no fueran de dicha compañia.., que han venido a caer en el mismo error, aunque algo mitigado, de Pelagiom. ${ }^{18}$

Pero volvamos al siglo XIV, regresemos con nuestro autor, Thomas Bradwardine, y veamos con mayor detenimiento cuáles son sus propuestas.

De las referencias de Bradwardine a las ya citadas condenas parisinas podemos extraer importantes datos; pero sobre todo destaca una idea clave para entender el planteamiento bradwardiniano: sólo si Dios es providente, está presente en todo y nada escapa a su voluntad, es posible defender la libertad en las voluntades creadas. En definitiva, que no es posible hablar de libertad en el hombre, sin afirmar la omnipotencia, la providencia y la libertad de Dios.

El Doctor Profundus reacciona contra quienes alejan a Dios del universo, evitando el contacto de lo perfecto con lo imperfecto; contra los defensores de un Dios de corte neoplatónico y de un universo en el que, no habiendo providencia, todo está sometido a un encadenamiento necesario de causas y efectos, carente de sentido-amor. Frente a todo esto nuestro autor reivindica un Dios personal e implicado en el mundo, es decir, providente.

Estamos ante la cuestión clave. Pero el asunto, como veremos, no es en absoluto sencillo. Bradwardine parece ver con claridad cuál es el problema: un universo independizado de Dios, la autonomía de lo creado respecto de su creador, harían que la filosofia, liberada de la metafísica o teología, terminase siendo física, y que no tuviese cabida hablar de libertad para el hombre (no estamos tan lejos de los problemas planteados por Kant). Ahora bien, la posición bradwardiniana implica algo que es necesario explicar: que el hombre, sometido a los decretos de la voluntad de Dios, aun así, es libre; más aún, que sólo sometido a los decretos de la voluntad divina es libre. Es la gran cuestión, es el objeto de estudio de todo el De Causa Dei, es el meollo de la disputa de «auxiliis» que tuvo enzarzados a dominicos y jeșitas durante al menos dos siglos.

16 Este asunto se encuentra explícitamente tratado en I. Verdú Berganza, «Precedentes medievales de las disputas...»; también resultan de interés: A. Bonet, La filosofia de la libertad en las controversias teológicas del siglo XVI y primera mitad del XVII, Barcelona, 1932; E. Portalié, «Augustinianisme (Développement historique)», en Dictionnaire de Theologie catholique, París, 1903-1950, tt. 1-2, col. 2536-2540; J. F. Genest, Prédétermination et liberté créée...

17 V. Beltrán de Heredia, Domingo Báñez y las controversias sobre la gracia. Textos y documentos, Salamanca, 1968, p.431 (en torno al papel del P. Suárez).

18 V. Beltrán de Heredia, Domingo Báñez y las controversias sobre la gracia... pp. 116 y 120. 
En la obra bradwardiniana quedan claros la necesidad de la iniciativa divina y el papel imprescindible de la gracia en orden a la salvación. ${ }^{19} \mathrm{El}$ hombre está liberado de la necesidad que supone estar por completo bajo el imperio de las causas segundas ${ }^{20}$ y está sometido a la voluntad divina; en esto consiste ser racional y libre, tener una dignidad superior a la del resto de las criaturas. Ahora bien, ¿de qué modo co-actúan, cooperan, en todo acto libre Dios y la voluntad creada? Aclarar esta dificultad fue el objetivo de Bradwardine, y conocer lo que propuso es nuestra próxima tarea.

«La tesis central del libro II (del De Causa Dei) es que la voluntad creada humana, como tal (ut voluntas) es por su propia naturaleza indeterminada y contingente (ad utrum libet), de modo que cuando un hombre ha elegido el curso de una acción, aún tiene el poder de elegir el opuesto (ibertas contradictionis); no obstante, para todo acto de una voluntad creada, Dios es necesario co-efector, de modo que el acto es totalmente producido por la voluntad creada, y, también, totalmente producido por Dios, la voluntad no creada (Capítulo XX). Asi, ambos, Dios y hombre, son causas co-eficientes de la realidad del acto, pero no como iguales (Capítulo $X X L X) »{ }^{21}$ Estas palabras de J.A. Weisheipl describen con suficiente claridad cuál es la cuestión. Nos sitúa ante el problema. Ahora hemos de adentrarnos en él.

La clave de todo el planteamiento bradwardiniano reside en que para nuestro autor en cualquier acto de la voluntad creada Dios es necesario coefector; si bien, siendo coeficientes las voluntades creada y no creada, Dios, la no creada, es siempre natural, que no temporalmente, antecedente. $^{22}$

La labor del Doctor Profundus a lo largo del primer capítulo, su afirmación de que la voluntad divina es causa eficiente de cualquier cosa que se haga, así como motor de cualquier movimiento, su insistencia en la inmediatez de la acción divina, en que «la voluntad divina es universalmente eficaz, insuperable, necesaria al causar, de ningún modo impedible o frustrables ${ }^{23}$; le conducen a afirmar la necesidad de Dios como co-actor de todo acto voluntario-libre, y su prioridad en la acción, respecto de toda voluntad creada. Así las cosas ¿Cómo puede decirse que la voluntad humana es una voluntad libre? Si la voluntad creada, al actuar, está siempre sometida a la voluntad divina, ¿en qué consiste su libertad?

Bradwardine marca claramente cuáles son los lindes del terreno que debemos investigar. Por un lado afirma, decididamente, la existencia del libre albedrio, entendido como una potencia racional capaz de juzgar racionalmente y decidir voluntariamente, se enfrenta a quienes niegan su existencia y especifica que lo propio de la libertad humana es ser «libertad de contradicción», es decir, la capacidad de elegir entre opciones opuestas. ${ }^{24}$ Pero, con igual contundencia, defiende que todo cuanto acontece, acontece necesariamente en relación a la primera causa, que es el querer divino. En definitiva, que todo acto y todo ser están sometidos a la necesidad, necesidad que llama «necesidad antecedente», identificada con los decretos de la voluntad de Dios. ${ }^{25}$

El Egregius Teologus, parece claro, defendía a la vez la «libertad de contradicción» (libertas contradiccionis) y la «necesidad naturalmente antecedente» (necesitas naturaliter an-

19 Esta idea es constante a lo largo del $D e$ Causa Dei, y de entre los múltiples pasajes que podrían citarse, indico algunos como mero ejemplo: del libro primero Cap. XL, p. 364 A; Cap. XLI, p. 371 A; Cap. XLII, p. 374 B; y del libro segundo Cap. IV, p. 472 A; Cap. V, p. 477 C; Cap. VI, p. 489 C; o Cap. VII, p. 490 C.

20 Th. Bradwardine, De Causa Dei, Lib. II, Cap. III, p. 466 D.

21 J. A. Weisheipl, "Ockham and the...», p. 652.

22 Th. Bradwardine, De Causa Dei, Lib. III, Cap. 53, Tesis 16, P. 875 B.

23 Th, Bradwardine, De Causa Dei, Lib. I, Cap. 10, p.195 B. Más referencias a este respecto pueden encontrarse en: I. Verdú Berganza, Tomás Bradwardine. El problema de la libertad... p. 127, notas. 70 y 73.

24 Th. Bradwardine, De Causa Dei, Lib. I, Cap. II, pp. 443 D y 444 B-C; Lib. II, Cap. 18, p. 529 A y Cap. 19, p. 538 B; Lib. III, Cap. 12, p. 688.

25 Th. Bradwardine, De Causa Dei, Lib. III, Cap. 2, 646 B-C. 
tecedens). Entender su propuesta exige por tanto profundizar aún más en lo que implican estos conceptos.

Los dógicos medievales distinguían con claridad dos tipos de necesidad: la necesidad de consecuente, absoluta o de re; y la necesidad de consecuencia, hipotética o de dicto. Sin embargo, Bradwardine añade otro término (Necesitas antecedens) y aborda la cuestión desde otra perspectiva. Lo que le interesa es resaltar el hecho de que todo ocurre necesariamente respecto de la voluntad divina, no porque Dios quiera «necesitar», "determinar», cualquier acto, sino porque es la Primera causa, universalmente eficaz, omnipotente, que no puede impedirse ${ }^{26}$; y no puede no serlo.

Todo cuanto acontece, pasado, presente y futuro, acontece, por tanto, necesariamente, pues, por necesidad naturalmente antecedente, no puede ocurrir sino lo que Dios, libremente, quiere que ocurra. Ahora bien, aceptado, de acuerdo con Duns Escoto, que la contingencia de una acción consiste en que lo opuesto de dicha acción particular pudiese igualmente haber tenido lugar ${ }^{27}$ y que, por tanto, toda acción contingente proviene de una libre elección, Bradwardine puede afirmar que tanto el futuro, como el presente y el pasado, en términos absolutos, son contingentes.

La fuente de toda necesidad; contingencia y libertad (de contradicción) está en Dios. En Dios convergen necesidad, contingencia y libertad. Pero ¿De qué modo pueden darse a la vez en el hombre necesidad y libertad? ¿Cómo puede afirmarse a la vez la libertad de elección y la necesidad de dicha elección?

En el capítulo segundo del tercer libro del De Causa Dei afirma Bradwardine «Que Dios, como necesidad naturalmente antecedente, de algún modo impele necesariamente a toda voluntad creada en su producción, cese o abstención libre de un acto $).{ }^{28}$ Es decir, que es Dios el que hace que hagamos lo que hacemos, pero lo que hacemos lo hacemos libremente. Una difícil concordia.

Ya años antes de escribir su obra cumbre, en su De futuris contingentibus, el Egregius Theologus afrontaba esta cuestión, y afirmaba: «La voluntad humana no escapa a la acción de Dios, pero cuando ésta (la acción divina) actúa sobre la voluntad humana, no la determina a la manera de una naturaleza; hace que se determine libre y voluntariamente $(51 f) \gg .{ }^{29} \mathrm{La}$ idea parece la siguiente: Dios quiere libremente que un acto sea hecho libremente, y su decreto hace que este acto libre sea, necesariamente. Dios es la fuente, el origen de toda contingencia y de toda libertad.

«Lo que Bradwardine quería decir era que Dios, como previo a las actividades de todas las criaturas, era una causa antecedente que mueve a todas las criaturas de acuerdo con sus propias naturalezas: necesariamente a las naturalezas determinadas y libremente a las naturalezas libres (ad utrum libet)». ${ }^{30}$ Cabría por tanto entender la acción de Dios, en tanto que necesaria y naturalmente antecedente, al menos de dos modos: ya nos refiramos a su acción sobre las naturalezas libres (voluntades creadas como la humana), ya a su acción sobre el resto de naturalezas (no libres).

Llegados a este punto, El Doctor Profundus, en el libro tercero del De Causa Dei, distingue dos tipos de necesidad (naturalmente antecedente): Una que repugna a la libertad y se caracteriza por ser «Natural, fatal y violenta $»^{31}$; y otra «espontánea y conforme a la libertad»,

26 Th. Bradwardine, De Causa Dei, Lib. III, Cap. I, p. 639 E y Lib. III, Cap. 2, p. 646 E.

27 N. Kretzman/A. Kenny/J. Pinborg (Eds.), the Cambridge history of later medieval Philosophy, Cambridge University Press, Cambridge, 1982, p. 276

28 Th. Bradwardine, De Causa Dei, Lib. III, Cap. 1, p. 637 B.

29. J. F. Genest, «Le de futuris contingentibus de...», p. 267.

30 J. A. Weisheipl, «Ockham and the...», p. 654.

31 Th. Bradwardine, De Causa Dei, Lib. III, Cap. 10, coroll., p. 686 C. 
compatible con el libre arbitrio de la voluntad. ${ }^{32}$ Parece claro que no es posible avanzar más en esta investigación sin esclarecer suficientemente qué es lo que entiende Bradwardine por libertad humana.

Siguiendo a E. Gilson, podría decirse que durante la Edad Media el término libertad (libertas) se entendió al menos de tres formas diferentes: como Libertas a necesitate, es decir, la libertad entendida como la capacidad de elegir libremente (el libre albedrío); como libertas a peccato, referida a la liberación de la servidumbre del pecado $\mathrm{y}$, por tanto, a al capacidad de hacer el bien; y como libertas a miseria, es decir, la que nos libera del sufrimiento y de la muerte. ${ }^{33}$

Aunque Bradwardine no utilizó directamente estos términos, es un hecho que abordó el problema de la libertad, con toda su complejidad, sin excluir ninguna de las acepciones citadas.

Como ya señalé anteriormente, el Magnus Logicus defendió el libre albedrío, la Libertas a necesitate, entendida como libertas contradiccionis. ${ }^{34}$ La idea es clara, el creado querer humano es, por su propia naturaleza, indeterminado y, en este sentido, contingente; y es que, en efecto, cuando un hombre ha elegido el curso de una acción, aún tiene el poder de elegir el opuesto, y esto es así porque entre dos opciones contrarias sólo si una de ellas es lógicamente imposible resulta necesaria la otra. Pero, a todo esto añade que dice albedrío porque hace referencia a los juicios de la razón o del intelecto, y libre porque hace referencia a la espontaneidad, es decir, a la falta de coacción, propia de la voluntad. ${ }^{35}$

Este es un punto importante. Aunque lo opuesto a lo elegido fuese posible, es decir, aunque lo elegido no sea necesario, si elegimos bajo coacción no somos libres. Y cuando Bradwardine habla de coacción se refiere a la que puedan ejercer las causas segundas. Es un «sinsentido» que lo querido por Dios pueda no acontecer, es decir, que Dios no sea omnipotente o infalible, $y$, en este sentido, no es razonable defender la libertad en el hombre y afirmar que es incompatible con la necesidad antecedente, Dios, causa primera. ${ }^{36}$ Pero, a su vez, no es posible hablar de libre albedrío si toda acción está determinada, si se actúa bajo coacción y no voluntariamente. ¿Qué significa, pues, actuar sin coacción y voluntariamente? La propuesta bradwardiniana, ya presente en el De futuris contingentibus, es que el hombre es libre porque se determina a sí mismo, actúa cuando quiere, de forma espontanea, sin que las causas segundas determinen su comportamiento. ${ }^{37}$

Ésta es la tesis defendida a lo largo del De Causa Dei. Basta con que el hombre no esté sometido a ninguna necesidad natural, con que ninguna causa inferior pueda obligar, de forma necesaria, a la voluntad creada en su producción de actos; basta con la espontaneidad, para que podamos hablar de libertad, de libre albedrío, en el hombre. Así, el hombre es dueño de sus propios actos, libre, lo que no quiere decir que no esté sometido a la voluntad de Dios, lo que sería imposible, absurdo.

De lo visto hasta ahora es posible sacar algunas conclusiones: En primer lugar, podemos afirmar que Bradwardine identifica la «necesidad naturalmente antecedente» con la voluntad

32 Th. Bradwardine, De Causa Dei, Lib. III, Cap. 11, p. 686 A.

33 Este modo de plantear la cuestión puede encontrarse en E. Gilson, El espiritu de la filosofia medieval, Rialp, Madrid, 1981.

34 Th. Bradwardine, De Causa Dei, Lib. III, Cap. 9, p. 675 A-B

35 Th. Bradwardine, De Causa Dei, Lib. II, Cap. 1, p. 443 D; Lib. III, Cap. 9, p. 676 C.

36 Este será uno de los problemas clave que estará a la base de la controversia De auxiliis, y que movilizó a importantes pensadores de los siglos XVI y XVII. De hecho, las similitudes entre las disputas habidas en el siglo $\mathrm{XIV}$, entre Bradwardine y los que él denomina pelagianos, y las acaecidas siglos después, entre dominicos y jesuitas, son realmente notables, lo que creo haber mostrado en el artículo ya citado: I. Verdú Berganza, «Precedentes medievales de las disputas sobre la libertad en las escuelas de Salamanca en los siglos XVI y XVII «.

37 J. F. Genest, « Le De futuris contingentibus de...», p. 276; Th. Bradwardine, De Causa Dei, Lib. II, Cap. 3, p. 449 A y coroll, p. 467 C-D; Lib. III, Cap. 11, 686 E. 
de Dios, que insiste en la inmediatez de la acción divina, y que, lógicamente, afirma la presencia activa de Dios, como causa primera, en cualquier actividad realizada por las voluntades creadas, finitas y contingentes (causas segundas). $Y$ en segundo lugar, que defiende la libertad propia del hombre, ser dotado de una voluntad activa, de libre albedrío, y responsable de sus acciones. Es decir, que afirma la presencia, en cualquier acción libre, de las voluntades creadas como causas activas e inmediatas.

Este planteamiento de la cuestión se adelanta en el tiempo a la tesis defendida en el siglo XVI por Domingo Báñez, frente a la «concordia» propuesta por Molina, y que se conoce como «concurso previo» $\mathrm{o}$ «premoción física». ${ }^{38}$ Ahora bien, ¿Dice algo Bradwardine acerca de la libertas a peccato y la libertas a miseria, asunto crucial en la disputa entre bañecianos y molinistas? Cómo ya he indicado, si bien no utiliza estos términos, desde luego si aborda las cuestiones a las que hacen referencia.

Uno de los asuntos fundamentales que enfrentó al Doctor Profundus con los pelagianos fue el de la capacidad del hombre para hacer el bien y así ser libre (libre de la esclavitud del pecado). No es en este caso la capacidad de elegir libre o espontáneamente lo que se plantea, sino el poder del hombre para elegir y hacer el bien libremente, junto con la necesidad o no, por parte del hombre, de la gracia de Dios para actuar moralmente bien, meritoriamente.

El pelagianismo exaltaba la naturaleza humana y el poder de su libertad de tal forma que no les era posible reconocer a la gracia como un don gratuito y necesario liberarse del pecado $\mathrm{y}$, desde luego, al mérito como algo dependiente de la gracia. Si el hombre era realmente libre, entonces no necesitaba de la gracia para ser bueno y merecer. Bradwardine, naturalmente, reacciona frente a esta posición.

Para el Egregius Theologus, de acuerdo con la línea agustiniana de pensamiento, la necesidad de la gracia no excluye la libertas a necesitate; pero sólo la gracia de Dios libera al hombre del pecado y lo capacita para hacer el bien. ${ }^{39}$ Así pues, afirma la necesidad de la gracia y se enfrenta a quienes consideran que existe oposición entre gracia y libre albedrio, presencia de Dios y perfeccionamiento del hombre.

Frente a Dios, que es el ser necesario, plenitud, acto puro, el bien, el hombre es sólo un ser posible que, aun siendo bueno, en tanto que es ser, no es necesario, es creado, es ser en potencia, en potencia por ejemplo de ser mejor, pero, por eso mismo, incompleto, imperfecto: está privado de ser, de bien, y, en este sentido, inclinado al mal. Como ser posible, en potencia, incompleto, imperfecto, necesita del ser necesario, acto puro, para ser y actuar. Pero, además, como ser privado de bien y en potencia de ser mejor, necesita igualmente del ser necesario, acto puro, bien, que le capacite para el bien. ${ }^{40}$

De acuerdo con lo expuesto, para Bradwardine, el hombre, aunque dotado de libre albedrío, sin la gracia no podría ser bueno (hacer el bien). Hacer el bien supone actuar libremente, ejercitar el libre albedrío, pero capacitado por la gracia. Es decir, la ausencia de gracia no implica la ausencia de libre albedrío, pero su presencia tampoco. Si al hablar de los actos propios de las voluntades creadas, como la humana, afirmaba que tales actos eran producidos inmediatamente por la voluntad humana y por la divina (que resultaba ser naturalmente antecedente), es lógico mantener la misma posición ahora. Y así, podemos leer en el De Causa Dei lo siguiente: «La gracia, que es un hábito gratuitamente dado por Dios, es, a la vez que la voluntad humana, causa eficiente de los actos buenos y meritorios (de dicha voluntad)» y «establecido que la gracia y la voluntad hacen conjuntas los buenos actos, digo que la gracia infundida gratuitamente es anterior naturalmente a la voluntad en la producción de los buenos

38 J. F. Genest, «Le de futuris contingentibus de...», p.267; I. Verdú Berganza, «Precedentes medievales de las disputas...», pp. 291-213.

39 L. F. Ladaria, Antropologia teológica, UPCM, Madrid, 1987, p. 284.

40 Th. Bradwardine, De Causa Dei, Lib. I, Cap. 1, p. 2 B-C y Cap. 43, p. 397 C-D. 
actos». ${ }^{41}$ «Cuando, dice (Agustín), Dios corona nuestros méritos, ninguna otra cosa corona que no sean sus dones». ${ }^{42}$

El hombre, que por naturaleza está liberado de la necesidad (Libertas a necesitate), por medio de la gracia queda capacitado para hacer libremente el bien, liberarse de su «inclinación al mal», el pecado (libertas a peccato).

Finalmente habría que decir que la gratuidad de la gracia y la necesidad de la misma suponen la gratuidad de la salvación (necesitas a miseria). Nada de lo que el hombre haga lo hará merecedor de la gloria, si no es porque Dios quiere que el hombre que libremente lo desee la alcance. ${ }^{43}$.

El hombre alcanza una dignidad superior a la del resto de las criaturas ya que es un ser creado a imagen y semejanza de Dios: racional y libre. Liberado de la necesidad, sólo está sometido a la inquebrantable voluntad divina. Y del mismo modo que Dios es la causa final última, de toda loa creación y de las acciones de todas las criaturas, el hombre será causa final (media, no última) de todas las demás criaturas, es decir, del resto de la creación. ${ }^{44}$

La obra del Doctor Profundus tuvo una indudable influencia en los siglos siguientes, y fue objeto de apasionadas defensas y duros ataques. La acusación fundamental, ya en el siglo XIV, era la de que eliminaba el libre albedrío y sostenía tesis deterministas. Sin embargo, por este mismo motivo, por su pretendido carácter determinista, fue también alabado; de hecho, autores como Juan Wyclef o Juan de Mirecourt lo citan en numerosas ocasiones ${ }^{45}$. Pero es en los siglos XVI y XVII cuando su influencia se hace más patente.

Se puede constatar como desde el siglo XVI, tanto en el mundo católico como en el protestante, se acude a su autoridad para afianzar las distintas opiniones. En 1552 Jorge Cassandre ofrecía un extracto del prefacio del De Causa Dei para los católicos; y en 1573, Flacius Illyricus, luterano combativo, en la tercera edición de su Catalogus testium veritatis, traducía al alemán el mismo prefacio y comunicaba su deseo de que apareciese una edición completa de la obra ${ }^{46}$.

Es en 1618 , en Londres, cuando se edita la obra ${ }^{47}$. Y es interesante saber que un librero de Francfort, Guillermo Serlin, hizo que se difundiese por terreno propiamente protestante ${ }^{48}$.

De entre los pensadores destacados de esta época que leyeron y citaron a Thomas Bradwardine el primero que ha de ser mencionado es Guillermo Twisse. Este brillante polemista había transcrito ya todo el De Causa Dei siendo bachiller de teología en Oxford, y en sus obras, sobre todo contra Suárez y los jesuitas, acudió al Doctor Profundus como autoridad irrefutable. ${ }^{49}$

41 Th. Bradwardine, De Causa Dei, Lib. I, Cap. 40, p. 364 A y Cap. 41, p. 371 A.

42 Th. Bradwardine, De Causa Dei, Lib. I, Cap. 39, p. 324 A.

43 Th. Bradwardine, De Causa Dei, Lib. I, Cap. 39, p. 356 E-357 A.

44 Th. Bradwardine, De Causa Dei, Lib. I, Cap. 21, p. 229 B-D.

45 Para conocer la relación de Juan Wyclef con Bradwardine es sumamente útil la ya citada obra de J. A. Robson: Wyclif and the Oxford schools; por su parte, la relación existente entre Juan de Mirecourt y nuestro autor está rigurosamente estudiada en los siguientes tratados: J. F. Genest, «Le de futuris contingentibus de...», pp. 268-272; C. Michalski, La philosophie au XIVe siècle, six études, Minerva, Francfort, 1969, en particular el estudio titulado «le probleme de la volonté à Oxford et à Paris au XIV siecle», pp. 279-413.

46 J. F. Genest, Prédétermination et liberté créée à Oxford..., p. 157, nota n. 792; Flacius Illyricus, Catalogus testium veritatis, Francfort, 1573, ff. CCLXXVII-CCLXXIX.

47 A. W. Pollard-R. Redgrave, A short Title Catalogue of Books Printed in England, Scotlant and Ireland, and English Books Printed Abroad, 1475-1640, Londres, 1926, p. 75, n' 3534.

48 Este volumen se encuentra en Mans. Bibl. Mun., Théol. 3068.

49 J. F. Genest, Prédétermination et liberté créée à Oxford... PP. 160-161; Guillelmus Twisse, Vindicae gratiae, protestatis ac providentiae Dei, hoc est ad examen libelli Perkinsiani de praedestinationis modo est ordine institutum a Jacobo Arminio responso..., Amsterdam, 1632, p. 142, col. b; Gillelmus Twisse, Dissertatio de scientia media, tribus libris absoluta, quorum prior Gabrielem penottum ad partes vocat in suo «libertatis humanae propugnaculo»...; posteriores duo Francisco Suaresio oppositi sunt, duosque libros eius «de scientia De» inscriptos refellendos suscipiunt..., Arnhein, 1639, pp. 130, 131, 266 y 267. 
Tras un siglo, el XVI, en el que dominicos y jesuitas discutieron vivamente los problemas expuestos en el De Causa Dei, en el siglo XVII, cuando estos problemas ya no estaban circunscritos a una disputa entre ordenes religiosas, cuando se planteaban también en el mundo protestante, no es de extrañar esta obra fuese publicada, y su autor recobrase de nuevo protagonismo.

Tras la publicación, en el terreno católico, algunos pensadores, sobre todo dominicos, adoptaron con entusiasmo las ideas de Bradwardine. Algunos ejemplos son los dominicos Juan González de León, Antonio Regnault (Reginaldus) o J. H. Serry. Por su parte, A. Arnaud, con quien Leibniz (conocedor de la obra del Doctor Profundus a quien cita en más de una ocasión $)^{50}$ mantuvo una intensa correspondencia y una gran amistad ${ }^{51}$, consideraba que Bradwardine era, de entre todos los antiguos escolásticos, el que mejor explicaba la gracia y su relación con el libre albedrío. ${ }^{52}$

Podrían citarse más autores, ya entrando el siglo XVIII, que mostraban su admiración; pero igual empeño pusieron sus detractores, de entre los que merece la pena citar al menos a Ricardo Simon $^{53}$, Juan Bautista Philippoteau Du Chesne ${ }^{54}$, uno de los más duros polemistas de la Compañía de Jesús, o Du Plessis D'Argentré y su Collectio judiciorum de novis erroribus... 55

En definitiva, las tesis bradwardinianas en torno a la libertad y la necesidad que ya hemos estudiado, el De Causa Dei, que es su exposición más completa, estuvieron presentes en las disputas filosóficas y teológicas desde el siglo XIV en adelante. Y su importancia fue tal que muchos autores llegaron a ensalzar a Bradwardine como el primero entre los escolásticos, otros lo consideraron de su propia orden religiosa, y, por último, los hubo que, con igual ardor, llegaron a condenarlo por hereje. Aún hoy en día su clasificación, su consideración como: determinista, pre-reformista, pre-bañeciano... está pendiente.

50 Leibniz no sólo citó a Bradwardine en su Teodicea, sino que hizo referencia a tanto a su persona como a su obra en otra serie de escritos inéditos en su tiempo, que hoy en día podemos investigar gracias a la edición que hizo de ellos Gastón Grua, Leibniz. Textes inédits, 2 vol., París, 1948.

51 G. W. Leibniz, Correspondencia con Arnaud, trad. Vicente P. Quintero, Losada, Buenos Aires, 1946.

52 A. Amaud, «Dissertatio theologica quadripartita... 1656», en Oeuvres, París-Lausana, 1775-1783, t. XX, p. 234; también resulta de gran interés sobre este asunto J. Laporte, La doctrine de Port-Royal, t. II-1, «Les verités de la Grâce, París, 1923, p. 426.

53 J. F. Genest, Prédétermination et liberté créée à Oxford..., pp.164-166; P. Auvray, Richard Simon, I8381712, Paris, 1974; R. Simon, Lettres Choisies de m. Simon, Amsterdam, 1730, 4 vol., t.IV, carta 31, pp.228-236,; R. Simon, Critique de la Bibliotèque de auteurs ecclésiastiques, París, 1730, 4 vol., t. I, pp. 360-362.

54 J. F. Genest, Prédétermination et liberté créée à Oxford..., pp. 166-167; J.B. Du Chesne, Le prédestinatianisme, ou les hérésies sur la prédestination et la réprobation, traité historique et theologique, París, 1724, Lib. IV, Caps. II-, «Prédestinatianisme de Thomas de Bradwardin»,pp. 239-250.

55 Du Plessis Dárgentré, Collectio judicorum de novis erroribus..., Prís, 1728-1736, 3 vol., t. I, pp.323-330; «Errores Thomae Bradwardini». 